\title{
Rancang Bangun Aplikasi Fasilitas Umum Berbasis Web Services
}

\author{
Nora Eligia Christian, Yaulie Deo. Y. Rindengan, Pinrolinvic D. K. Manembu \\ Teknik Informatika Universitas Sam Ratulangi Manado, Indonesia. \\ nora.eligia.christian@gmail.com, rindengan@unsrat.ac.id,pinrolinvic@gmail.com
}

\begin{abstract}
Abstrak -Fasilitas umum merupakan sarana yang dibutuhkan oleh masyarakat.Begitu pula dengan informasi fasilitas umum.Dibutuhkan informasi yang dapat diperoleh dengan cepat dan akurat.Untuk menjawab kebutuhan mayarakat, maka dibutuhkan sebuah aplikasi yang dapat memberikan informasi dengan cepat dan akurat.Aplikasi ini dibuat berbasis web service sehingga memudahkan pihak luar untuk memperoleh informasi yang akurat yang dapat diolah berdasarkan kebutuhan.Client aplikasi ini dibuat berbasis Android yang terhubung dengan layanan google maps.Sehingga masyarakat yang menggunakan smartphone android dapat dengan mudah memperoleh informasi tersebut karena informasi lokasi yang ditampilkan dalam bentuk peta digital.Dalam penelitian ini menggunakan metode DAD (Disciplined Agile Delivery).Metode DAD terdiri atas 3 fase yaitu fase inception, fase construction dan fase transition.Berdasarkan dengan hasil penelitian dapat disimpulkan bahwa aplikasi fasilitas umum ini dapat membantu pengguna dalam memperoleh informasi dengan cepat dan akurat.Selain itu aplikasi ini juga membantu pihak luar untuk memperoleh data yang akurat yang dapat diolah berdasarkan kenutuhan pengguna.
\end{abstract}

Kata kunci :Fasilitas Umum, Web Services, Android, DAD (Disciplined Agile Delivery).

\section{PENDAHULUAN}

Perkembangan teknologi yang semakin pesat, sehingga segala sesuatu dituntut untuk lebih cepat dan mudah.Begitupun halnya dengan memperoleh informasi.Kita pasti menginginkan informasi yang kita butuhkan itu dapat diperoleh dengan mudah dan cepat.Dengan teknologi informasi yang berkembang saat ini, pengelolaan informasi dapat dilakukan secara lebih aktual dan optimal.Penggunaan teknologi informasi bertujuan untuk mencapai efisiensi dalam berbagai aspek pengelolaan informasi, yang ditunjukkan dengan kecepatan dan ketepatan waktu serta ketelitian dan keakuratan informasi.Dimana informasi tersebut dibutuhkan oleh berbagai pihak, seperti instansi pemerintah, pelaku bisnis, wisatawan, maupun masyarakat umum untuk dimanfaatkan sesuai keperluan masing-masing.

Seringkali kita berada pada situasi di mana sangat membutuhkan informasi tempat-tempat yang akandituju dalam keadaan yang sangat mendesak, akan tetapi kita kurang memiliki informasi yang dapat diperoleh dengan cepat dan mudah. Seperti yang kita ketahui bahwa fasilitas umum adalah fasilitas yang diadakan untuk kepentingan umum dan sangat dibutuhkan oleh masyarakat.Begitu pula dengan lokasi fasilitas umum.

Dari latar belakang tersebut membuat penulis berinisiatif untuk membuat sebuah aplikasi yang dapat memberikan informasi secara detail mengenai keberadaan fasilitas-fasilitas umum khususnya di Manado. Aplikasi tersebut berbasis web services sehingga memudahkan pengguna dalam memperoleh data yang akurat sehingga dapat diolah berdasarkan dengan kebutuhan. Client dari aplikasi ini akan dibuat dengan menggunakanplatform android. Dimana android merupakan platform yang sudah sangat familiar dikalangan masyarakat.

\section{LANDASAN TEORI}

\section{A. Fasilitas Umum}

Menurut Peraturan Menteri Dalam Negeri Nomor 9 Tahun 2009, tentang Pedoman Penyerahan Prasarana, sarana dan Utilitas Perumahan dan Permukiman, termuat definisi akan sarana, yaitu fasilitas yang dibutuhkan masyarakat dalam lingkungan permukiman yang meliputi fasilitas kesehatan, pendidikan, perbelanjaan dan niaga, peribadatan, rekreasi, budaya, olahraga dan taman bermain, Pemerintahan dan pelayanan umum serta pemakaman umum. Sedangkan prasarana lingkungan meliputi jalan, saluran pembuangan air limbah dan saluran pembuangan air hujan serta utilitas umum terdiri dari jaringan air bersih, jaringan listrik, jaringan gas, jaringan telepon, kebersihan/pembuangan sampah dan pemadam kebakaran. Prasarana, sarana dan utilitas dikenal dengan istilah fasilitas sosial dan fasilitas umum.(Tamsir,2012)

\section{B. Web Services}

Web services adalah aplikasi yang dibuat agar dapat dipanggil atau diakses oleh aplikasi lain melalui internet dengan menggunakan format pertukaran data sebagai format pengiriman pesan. Format pertukaran data dapat dilakukan dengan dengan XML dan JSON.Sebuah Web Services dapat dipanggil oleh aplikasi dengan menggunakan bantuan HTTP (HyperText Transfer Protocol).Web services juga memungkinkan untuk dipanggil dengan dengan menggunakan protokol lain seperti SMPT (Simple Mail Transfer Protocol), namun yang paling umum digunakan HTTP. Karena Web services menggunakan protokol HTTP, tentu PHP sebagai bahasa pemrograman web menjadi salah satu kekuatan bahasa pemrograman yang mengelola web services. (Kasman,2015)

C. REST

REST adalah gaya arsitektur perangkat lunak yang dapat digunakan saat merancang sistem perangkat lunak. 
REST merupakan desai yang ideal yang untuk perangkat lunak layanan berbasis web. Prinsip - prinsip dalam RESTyaitu :

- Menyediakan setiap sumber daya dengan $I D$ yang unik, misalnya $U R I$

- sumber daya URI link dengan satu sama lain, membangun hubungan antara sumber daya

- Gunakan metode standar (HTTP, jenis media, $X M L)$

- Sumber Daya dapat memiliki beberapa representasi yang mencerminkan negara aplikasi yang berbeda

- $\quad$ komunikasi harus menggunakan HTTP

Apabila kita menggunakan REST, pendekatan Client dan Server digunakan user terpisah dari penyimpanan data.Interaksi antara client dan server menggunakan antarmuka seragam.Salah satu kunci element dalam arsitektur adalah konsep resource dimana setiap informasi dapat menjadi resource.Setiap informasi memiliki URI sendiri yang merupakan prinsip utama dari Web Semantic yang berkembang dari World Wide Web di mana semantik informasi dan layanan di Web didefinisikan. Sebuah resource juga dapat memiliki representasi terkait, sebuah dokumen dapat menjadi dokumen $H T M L$, gambar dapat format JPEGdan data cuaca dapat direpresentasikan dengan menggunakan dokumen $X M L$.Sebuah sumber daya yang diberikan juga dapat memiliki metadata yang terkait seperti media-jenis dan bertahan saat dimodifikasi.

Ketika mengakses sumber daya dengan HTTP, pengenal sumber daya ditentukan bersama dengan tindakan yang akan dilakukan pada sumber daya itu. URI mengidentifikasi sumber daya.tindakan yang akan dilakukan didefinisikan menggunakan kata kerja HTTP. Ada satu set kata kerja HTTP dan setiap kata kerja dapat memiliki semantik terkait yang membantu untuk mengidentifikasi tindakan yang akan dilakukan pada sumber daya. Tabel berikut merangkum kata kerja HTTP dan bagaimana mereka berlaku saat menggunakan REST.

TABEL 1 PENJELASAN VERB DI HTTP

\begin{tabular}{|l|l|}
\hline \multicolumn{1}{|c|}{ Verb } & \multicolumn{1}{|c|}{ Deskripsi } \\
\hline GET & $\begin{array}{l}\text { Mengambil sumber daya diidentifikasi oleh } \\
\text { URI. }\end{array}$ \\
\hline POST & $\begin{array}{l}\text { Mengirim sumber daya ke server. Update } \\
\text { sumber daya di lokasi yang diidentifikasi } \\
\text { oleh URI. }\end{array}$ \\
\hline PUT & $\begin{array}{l}\text { Mengirim sumber daya ke server, untuk } \\
\text { disimpan di lokasi yang diidentifikasi oleh } \\
\text { URI. }\end{array}$ \\
\hline DELETE & $\begin{array}{l}\text { Menghapus sumber daya diidentifikasi oleh } \\
\text { URI. }\end{array}$ \\
\hline$H E A D$ & $\begin{array}{l}\text { Mengambil metadata dari sumber daya } \\
\text { diidentifikasi oleh URI. }\end{array}$ \\
\hline
\end{tabular}

\section{JSON (JavaScript Object Notation)}

JSON (Java Script Object Notation) adalah format pertukaran data yang ringan, mudah dibaca dan ditulis oleh manusia, serta mudah diterjemahkan dan dibuat (generate) oleh komputer.Format ini dibuat berdasarkan bagian dari Bahasa Pemrograman JavaScript, Standart ECMA-262 Edisi ke-3-Desember 1999. JSON merupakan format teks yang tidak tergantung pada bahasa pemrograman apapun karena menggunakan gaya bahasa yang umum digunakan oleh programmer keluarga $\mathrm{C}$, termasuk $\mathrm{C}, \mathrm{C}++, \mathrm{C} \#$, Java, JavaScript, Perl, Python dan lain-lain. Oleh karena sifatsifat tersebut, menjadikan JSON ideal sebagai bahasa pertukaran data. (Kasman,2015).

\section{E. Google Maps}

Google Maps adalah layanan pemetaan desktop yang web yang dikembangkan oleh Google. Menawarkan citra satelit, peta jalan, $360^{\circ}$ panorama jalan-jalan (Street View), kondisi lalu lintas real-time (Google Traffic), dan perencanaan rute untuk bepergian dengan berjalan kaki, mobil, sepeda (dalam versi beta), atau angkutan umum.Google Maps dimulai sebagai program desktop $\mathrm{C}$ ++ dirancang oleh Lars dan Jens Rasmussen Eilstrup pada Where 2 Technologies.Layanan ini menggunakan Javascript, XML, dan Ajax. Google Maps menawarkan API yang memungkinkan peta untuk dimasukkan pada situs web pihak ketiga, dan menawarkan locator untuk bisnis perkotaan dan organisasi lainnya di berbagai negara di seluruh dunia. Google Map Maker memungkinkan pengguna untuk bersama-sama mengembangkan dan memperbarui pemetaan layanan di seluruh dunia. (Raymond,2016).

\section{F. Google Maps API}

Google Maps API adalah kumpulan API yang memungkinkan Kita menghamparkan data di Google Map yang disesuaikan. Kita dapat membuat aplikasi web dan seluler yang menarik dengan platform pemetaan canggih dari Google, termasuk data citra satelit, Street View, profil ketinggian, petunjuk arah mengemudi, peta bergaya, analisis, dan basis data tempat yang luas. Dengan cakupan global yang paling akurat di dunia dan komunitas pemetaan yang aktif dalam membuat pembaruan setiap harinya, pengguna akan mendapatkan manfaat dari layanan yang terus-menerus ditingkatkan.

\section{G. Android}

Android adalah sistem operasi berbasis Linux yang dirancang untuk operasi perangkat seluler layar sentuh sepertitelepon pintar dan komputer tablet. Android awalnya dikembangkan oleh Android. Antarmuka pengguna Android didasarkan pada manipulasi langsung, menggunakan masukan sentuh yang serupa dengan tindakan di dunia nyata, seperti menggesek, mengetuk, mencubit, dan membalikkan cubitan untuk memanipulasi objek di layar. Android adalah sistem operasi dengan sumber terbuka, dan Google merilis kodenya di bawah Lisensi Apache. Kode dengan sumber terbuka dan lisensi perizinan pada Android memungkinkan perangkat lunak untuk dimodifikasi secara bebas dan didistribusikan oleh para pembuat perangkat, operator nirkabel, dan pengembang aplikasi.Android memiliki sejumlah besar 
komunitas pengembang aplikasi (apps) yang memperluas fungsionalitas perangkat, umumnya ditulis dalam versi kustomisasi bahasa pemrograman Java. Sifat Android yang terbuka telah mendorong munculnya sejumlah besar komunitas pengembang aplikasi untuk menggunakan kode sumber terbuka sebagai dasar proyek pembuatan aplikasi, dengan menambahkan fitur-fitur baru bagi pengguna tingkat lanjut atau mengoperasikan Android pada perangkat yang secara resmi dirilis dengan menggunakan sistem operasi lain.

\section{METODOLOGI PENELITIAN}

\section{A. Pengumpulan data}

Adapun pengumpulan data yang dilakukan oleh peneliti agar dapat menjadi suatu bukti dalam melakukan kajian antara lain. Pengumpulan data yang dilakukan yaitu dengan cara melakukan survei langsung di lokasi tujuan dengan menggunakan GPS Garmin Ertex.

\section{B. Metodologi Perancangan Sistem}

Pada tahap ini menggunakan metodologi DAD dimana terdapat 3 fase pengembangan yaitu fase inception, fase construction, dan fase transition.

\section{Fase Inception}

Pada fase ini merupakan fase awal perancangan sistem yang mengumpulkan semua kebutuhan-kebutuhan yang akan digunakan dalam mengembangkan sistem.

\section{Fase Construction}

Pada fase ini kegiatan yang dilakukan antara lain memodelkan, membangun sistem dan membuat dokumentasi.

\section{Fase Transition}

Meliputi aktifitas me-review kembali sistem aplikasi dan menginstalasi sistem aplikasi.

\section{HASIL DAN PEMBAHASAN}

\section{A. Fase Inception}

Pada fase ini merupakan fase awal perancangan sistem yang mengumpulkan semua kebutuhan-kebutuhan yang akan digunakan dalam mengembangkan sistem.

\section{TABEL 2.KEBUTUHAN PENGGUNA}

\begin{tabular}{|l|l|}
\hline Masalah & $\begin{array}{l}\text { Masyarakat tidak mengetahui lokasi } \\
\text { fasilitas umum } \\
\text { secara detail }\end{array}$ \\
\hline Menyebabkan & $\begin{array}{l}\text { Proses untuk mengetahui lokasi } \\
\text { fasilitas umum membutuhkan waktu } \\
\text { yang banyak }\end{array}$ \\
\hline $\begin{array}{l}\text { Dampak yang } \\
\text { ditimbulkan }\end{array}$ & $\begin{array}{l}\text { Lamanya memperoleh informasi } \\
\text { diimplementasikan }\end{array}$ \\
\hline Solusi yang & $\begin{array}{l}\text { Aplikasi yang dapat memberikan } \\
\text { menunjukan posisinya pada peta } \\
\text { Kota Manado dengan cepat dan } \\
\text { akurat }\end{array}$ \\
\hline
\end{tabular}

B. FaseConstruction

Pada fase ini kegiatan yang dilakukan antara lain memodelkan, membangun sistem dan membuat dokumentasi. Diagram-diagram yang dihasilkan adalah Use Case,UMLSequence Diagram dan Deployment View.

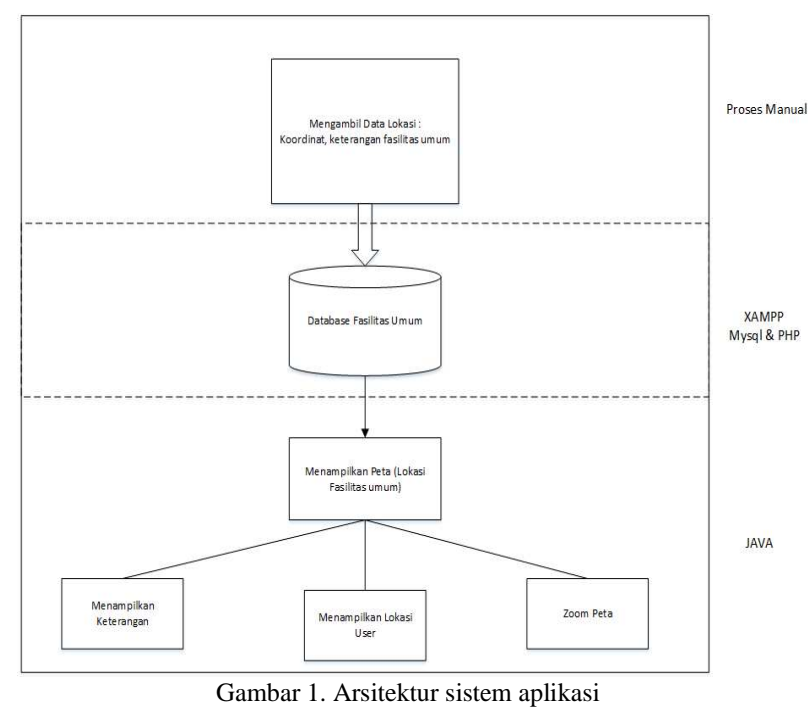

Pada Gambar 1 dapat kita lihat bahwa aplikasi ini dirancang meliputi 3 bagian besar yaitu proses manual dalam pengambilan data, XAMPP MySQL dan PHP dalam pengolahan database serverfasilitas umum dan pembuatan aplikasiclient untuk useryang ditulis dalam bahasa pemrograman Java.

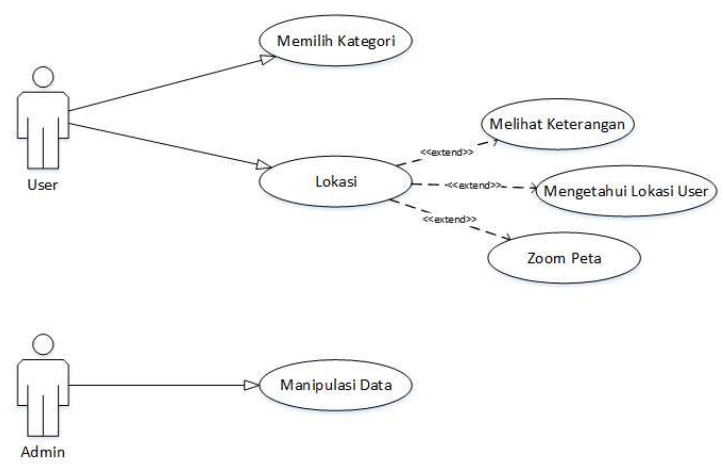

Gambar 2 Use case Diagram

Use case diagram pada Gambar 2 menggambarkan hubungan antara aktor dengan sistem. Pada use case diagram ini terdapat 2 aktor yaitu user dan admin. User dapat memilih kategori, dan melihat lokasi. Dan ketika user melihat lokasi, user dapat melihat katerangan dimana lokasi tersebut berada, dapat mengetahui lokasi user saat ini dan user dapat melakukan zoom peta.Sedangkan admin dapat melakukan manipulasi data yaitu admin dapat menginput, melihat, meng-update, dan menghapus data.

Sequence diagram pada Gambar 3 memberikan gambaran tentang apa yang akan dilakukan dalam aplikasi. Aplikasi yang dimaksudkan pada sequencediagram ini merupakan aplikasi client yang dibuat berbasis android 

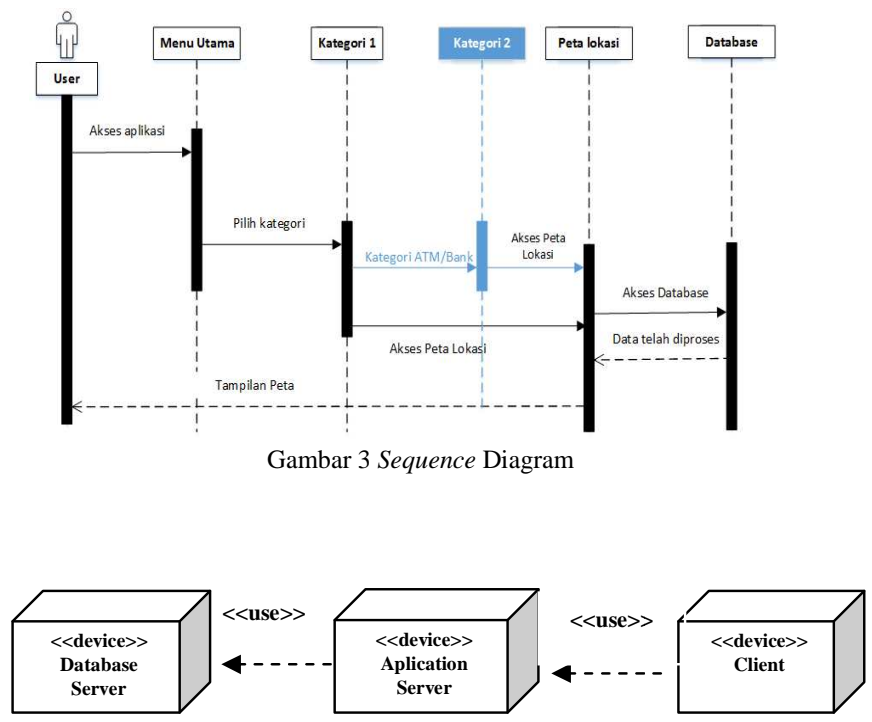

Gambar 4 Deployment Diagram

Deployment diagram menjelaskan bagaimana hubungan antara perangkat keras serta perngkat lunak dalam sistem dan distribusi fisik pengolahan sistem.

\section{Fase Transition}

Pada tahap ini kita akan me-review kembali sistem aplikasi yang telah dibuat. Aplikasi yang telah dibuat merupakan aplikasi fasilitas umum berbasis web services dengan menggunakan gaya arsitektur REST dan format pertukaran data JSON. Server dalam aplikasi ini dibuat dengan menggunakan method POST dan URI pada tabel 4.2 akan dimasukan dalam setiap source code untuk pembuatan aplikasi.

TABEL 3 IMPLEMENTASI REST

\begin{tabular}{|c|c|c|}
\hline $\begin{array}{l}\text { HTTP } \\
\text { Method }\end{array}$ & URI & Description \\
\hline POST & $\begin{array}{l}\text { /skripsi/webservice } \\
\text { s/all.php }\end{array}$ & $\begin{array}{l}\text { Menampilkan semua data } \\
\text { fasilitas umum }\end{array}$ \\
\hline POST & $\begin{array}{l}\text { /skripsi/webservice } \\
\text { s/get.php?id= } \\
\text { \{fasilitas_umum }\end{array}$ & $\begin{array}{l}\text { Menampilkan data } \\
\text { berdasarkan id }\end{array}$ \\
\hline POST & $\begin{array}{l}\text { /skripsi/webservice } \\
\text { s/update.php }\end{array}$ & Meng-update data \\
\hline POST & $\begin{array}{l}\text { /skripsi/webservice } \\
\text { s/simpan.php }\end{array}$ & Menginput data \\
\hline POST & $\begin{array}{l}\text { /skripsi/webservice } \\
\text { s/hapus.php }\end{array}$ & Menghapus data \\
\hline POST & $\begin{array}{l}\text { /skripsi/webservice } \\
\text { s/lokasi.php?kat }=\{\mathrm{i} \\
\text { d_kategori }\} \& \text { sub }=\{ \\
\text { id_subkategori }\} ;\end{array}$ & $\begin{array}{lr}\text { Menampilkan } & \text { lokasi } \\
\text { berdasarkan } & \text { dengan } \\
\text { kategori dan } & \text { subkategori } \\
\text { yang ada } & \end{array}$ \\
\hline
\end{tabular}

Pada Gambar 5 sampai Gambar 7 merupakan aplikasi client untuk admin yang telah dibuat untuk menampilkan semua data fasilitas umum, menghapus data, menginput data dan mengedit data. Sedangkan Gambar 4.8 merupakan aplikasi client untuk user berbasis Android yang dibuat menggunakan URI :

/skripsi/webservices/lokasi.php?kat $=\{$ id_kategori $\} \&$ sub $=\{\mathrm{i}$ d_subkategori\};
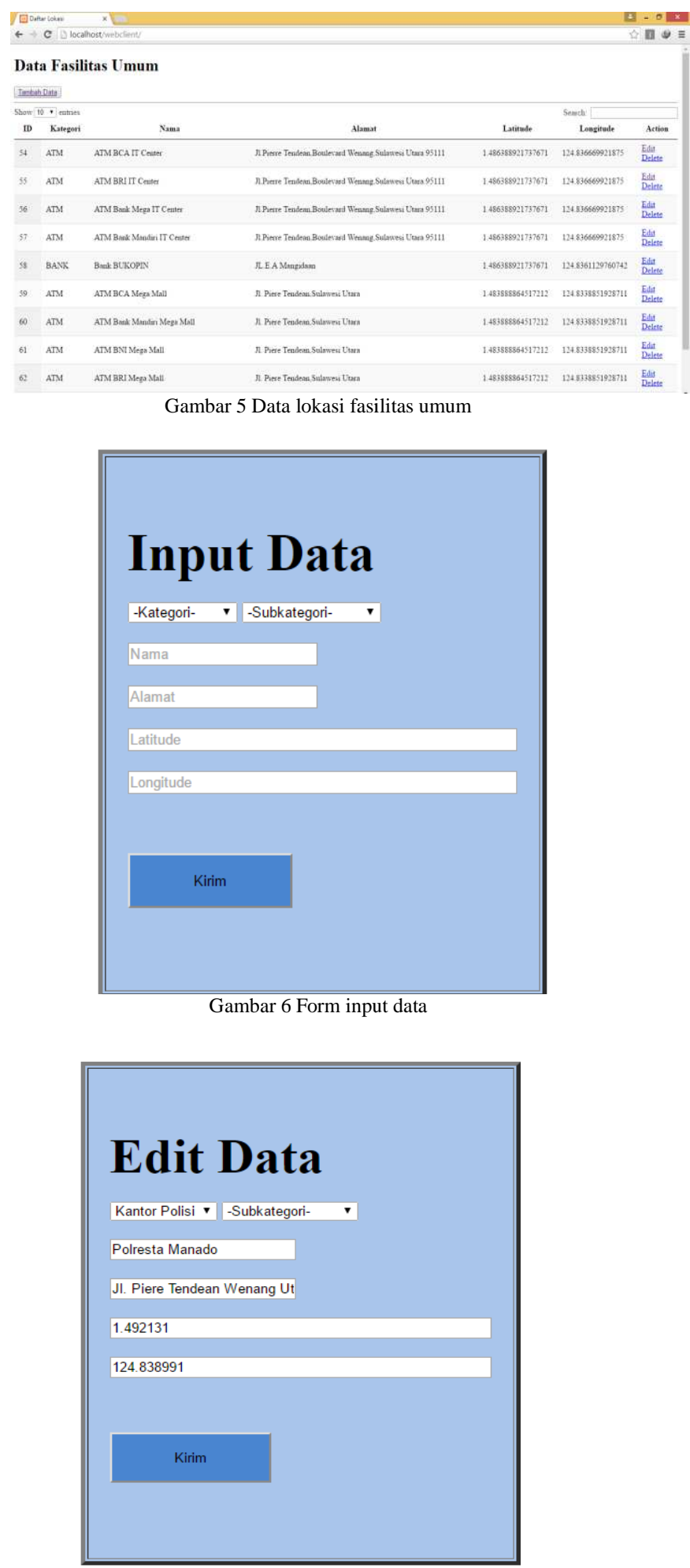

Gambar 7 Form input data 


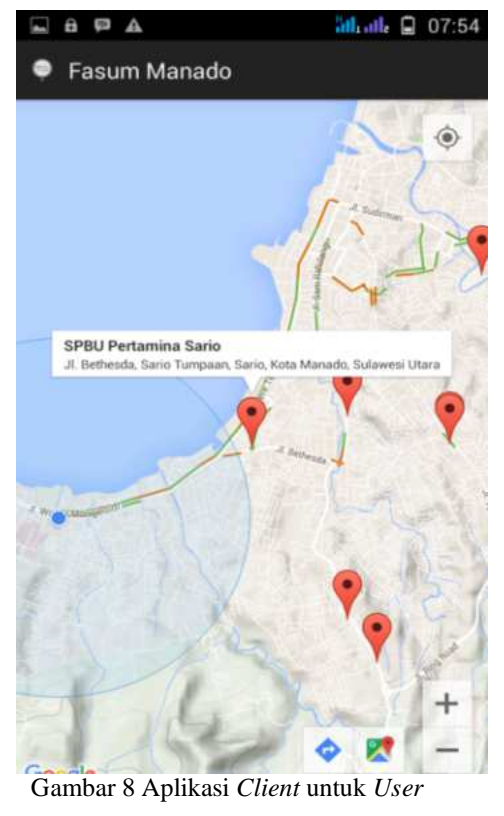

\section{PENUTUP}

A. Kesimpulan

1. Aplikasi fasilitas umum berbasis web services dengan menggunakan gaya arsitektur resttelah berjalan dengan baik.

2. Telah dibuat sebuah aplikasi client berbasis android yang telah berjalan dengan baik sesuai dengan kebutuhan user.

3. Data fasilitas umum yang diberikan merupakan data akurat.

\section{B. Saran}

Berikut merupakan saran yang berkaitan dengan pengembangan aplikasi ini lebuh lanjut yaitu diharapkan menggunakan server yang bebas dari gangguan agar data dapat selalu diakses.

\section{DAFTAR PUSTAKA}

[1] Abeysinghe Samisa "Restful PHP Web Services" Birmingham : Packt Publishing Ltd, 2008

[2] Kasman Akhmad "Trik Kolaborasi Android dengan PHP \& Mysql” Jakarta : LokoMedia, 2015

[3] Olii Marlon, Rindengan Yaulie, Tuturoong Nancy "Analisa dan Perancangan Aplikasi Penilaian Pegawai dalam Jabatan Struktural do Pemerintahan Kota Manado", 2014. Manado e-journal

[4] Kawulur Silvana, Rindengan Yaulie, Karouw Stanley, Robot Jimmy, "Perancangan Sistem Informasi Geografis Ruang Terbuka Hijau di Kota Manado", Manado e-journal

[5] Pakpahan Tigor, Rindengan Yaulie, Najoan Xaverius "Aplikasi Mobile Peta Rawan Bencana Kota Manado Berbasis Android" vol.2 No. 4 (2013), Manado ejournal.

[6] Susanto Raymond (2016, februari 14) Google Maps [online]

:https://id.wikipedia.org/wiki/Google_Maps
[7] Tamsir Rifky "Tinjauan Yurisida Terhadap Fasilitas Sosial (Fasos) dan Fasilitas Umum pada Perumahan dan Kawasan Pemukinan di Kota Makasar", (2012), Makasar e-journal

[9] Kasman Akhmad "Trik Kolaborasi Android dengan PHP \& Mysql” Jakarta : LokoMedia, 2015

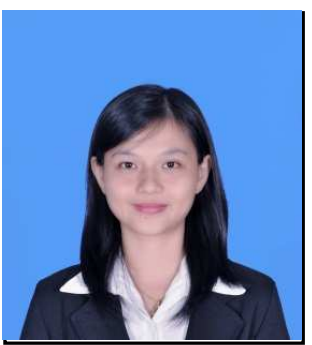

Sekilas dari penulis dengan nama lengkap Nora Eligia Christian, lahir di Kota Singkawang, Provinsi Kalimantan Barat. Anak ke-2 dari 4 bersaudara.Dengan pendidikan Sekolah Dasar Katolik St. Theresia, Malalayang 1 Barat, Manado.Kemudian Melanjutkan ke Sekolah Menengah Pertama Katolik St. Theresia, Malalayang 1 Barat.Kemudian melanjutkan ke Sekolah Menengah Atas SMAN 1Manado. Setelah lulus tahun 2011 melanjutkan ke Perguruan Tinggi di Universitas Sam Ratulangi Manado dengan mengambil Jurusan Teknik Informatika. Pada tahun 2015 bulan januari, penulis membuat Skripsi demi memenuhi syarat Sarjana (S1) dengan penelitian berjudul Rancang Bangun Aplikasi Fasilitas Umum Berbasis Web Services yang dibimbing oleh dua dosen pembimbing yaitu Yaulie D. Y. Rindengan, ST., MM., MSc dan Pinrolinvic Manembu, ST., MT sehingga pada tanggal 18 April 2016 penulis resmi lulus di Teknik Informatika Universitas Sam Ratulangi Manado dan menyandang gelar Sarjana Komputer dengan predikat Sangat Memuaskan. 